\title{
Multidrug Resistant Tuberculosis; a Pharmacological view based on Revised National Tuberculosis Control Programme DOTS-Plus Guidelines.
}

\author{
Harminder Singh $^{1^{*}}$, Kamalpreet Kaur ${ }^{2}$, Girish $\mathrm{P}^{3}$ \\ ${ }^{1-3}$ (Department of Pharmacology, Guru Gobind Singh, Medical College, Baba Farid University of Health \\ Sciences, Faridkot, Punjab.
}

\begin{abstract}
Directly Observed Therapy Strategy (DOTS) -Plus is a part of DOTS program that adds approach for multidrug resistance tuberculosis (MDR-TB) diagnosis, management, and treatment. WHO approved DOTS-Plus program began in 2000 and was established to encourage access to high quality second line drugs for appropriate use in MDR-TB control programs. The top priority is to prevent the emergence of MDR-TB by ensuring a low default rate of cases treated with first-line anti-TB drugs. If MDR-TB has emerged in a certain area, it should be treated in addition to improving the basic treatment. In this situation, accurate and reliable drug susceptibility testing, methods to support patients in order to ensure direct observation of complete treatment and the use of maximally effective regimens must be ensured. Second-line drugs should not be held back in patients with MDR-TB rather they have a good chance of cure with it, hence the treatment, if it is to be provided, should be optimally selected and administered. This review is highlighting the pharmacological view point of second line anti tubercular drug incorporated in DOTS-Plus therapy for MDR-TB.
\end{abstract}

Keywords - DOTS-Plus therapy, DOTS, MDR-TB, Adverse drug reactions, Drug resistant

\section{INTRODUCTION}

Multidrug resistance tuberculosis is defined as a form of tuberculosis (TB) due to Mycobacterium (M) tuberculosis that is resistant to at least isoniazid and rifampicin, the two most powerful anti-TB drugs. This form of TB was documented in nearly every country surveyed by the World Health Organization., ${ }^{1,2}$

With the implementation of the internationally accepted Directly Observed Therapy( DOTS) strategy for TB control and its essential component of standardized short-course chemotherapy (SCC), a comprehensive control strategy is available that, when followed properly, prevents the emergence of drug resistance. All currently optional regimens are based upon the first-line drugs isoniazid, rifampicin, pyrazinamide, ethambutol and streptomycin. ${ }^{3}$

Unfortunately, some of the same principles promoting resistance in patients in the 1950s remain intact and prevalent today, in combination with other new factors: lack of adherence to treatment, use of low quality drugs, improper diagnosis of TB patients, and lack of use of standard SCC. ${ }^{4}$

It is known that, MDR-TB patients are resistant to at least the two anchor drugs of SCC, a supplement to the DOTS strategy is now needed for the management of these patients. This is further supported by evidence showing that SCC offers cure rates of on average 52\% and 29\% in new MDR-TB patients and re-treatment MDR-TB cases, respectively. ${ }^{5}$

To address MDR-TB in low- and middle-income settings, the World health organization (WHO) and its partners created "DOTS- Plus for MDR-TB" a management strategy built upon the foundation and principles of DOTS. The first WHO endorsed DOTS-Plus programmes began in 2000. At that time, the Green Light Committee (GLC) was established to promote access to high quality second-line drugs for appropriate use in TB control programmes. ${ }^{6}$

Magnitude of the MDR-TB problem in India

Data from studies conducted by Tuberculosis Research Centre (TRC) and National Tuberculosis Institute (NTI), have found MDR-TB levels of less than 1\% to 3\% in new cases and around $12 \%$ in re-treatment cases. $^{7,8}$

Revised National Tuberculosis Control Programme (RNTCP) has recently undertaken two; community based state level drug resistance surveillance (DRS) studies in Gujarat and Maharashtra. These surveys have 
been conducted as per a common generic protocol based on internationally accepted methodology and have estimated the prevalence of MDR-TB to be about 3\% in new cases and $12-17 \%$ in re-treatment case. ${ }^{9}$

\section{Causes of drug-resistant tuberculosis}

Table.1 summarizes the common causes of inadequate treatment. However it should be stressed that MDR-TB is a man-made phenomenon - poor treatment, poor drugs and poor adherence lead to the development of MDRTB. ${ }^{4}$ (fig. 1 )

Table.1 Common causes of inadequate treatment

\begin{tabular}{|l|l|l|}
\hline $\begin{array}{l}\text { Providers/Programmes: } \\
\text { Inadequate regimens }\end{array}$ & $\begin{array}{l}\text { Drugs: } \\
\text { Inadequate supply/quality }\end{array}$ & $\begin{array}{l}\text { Patients: } \\
\text { Inadequate drug intake }\end{array}$ \\
\hline -Absence of guidelines or & -Non-availability of certain & -Poor adherence (or poor \\
inappropriate guidelines & drugs (Out of stock or delivery & $\begin{array}{l}\text { DOT) } \\
\text {-Non-compliance with }\end{array}$ \\
disruptions) & -Lack of information \\
guidelines & -Poor quality & -Non-availability of free drugs \\
-Inadequate training of health & -Poor storage conditions & -Adverse drug reactions \\
staff & -Wrong dosages or & -Social and economic barriers \\
-No monitoring of treatment & combination & -Malabsorption \\
-Poorly organized or funded & & -Substance abuse disorders \\
TB control programmes & & \\
\hline
\end{tabular}

Revised National Tuberculosis Control Programme, DOTS-Plus Guidelines FEB-2009

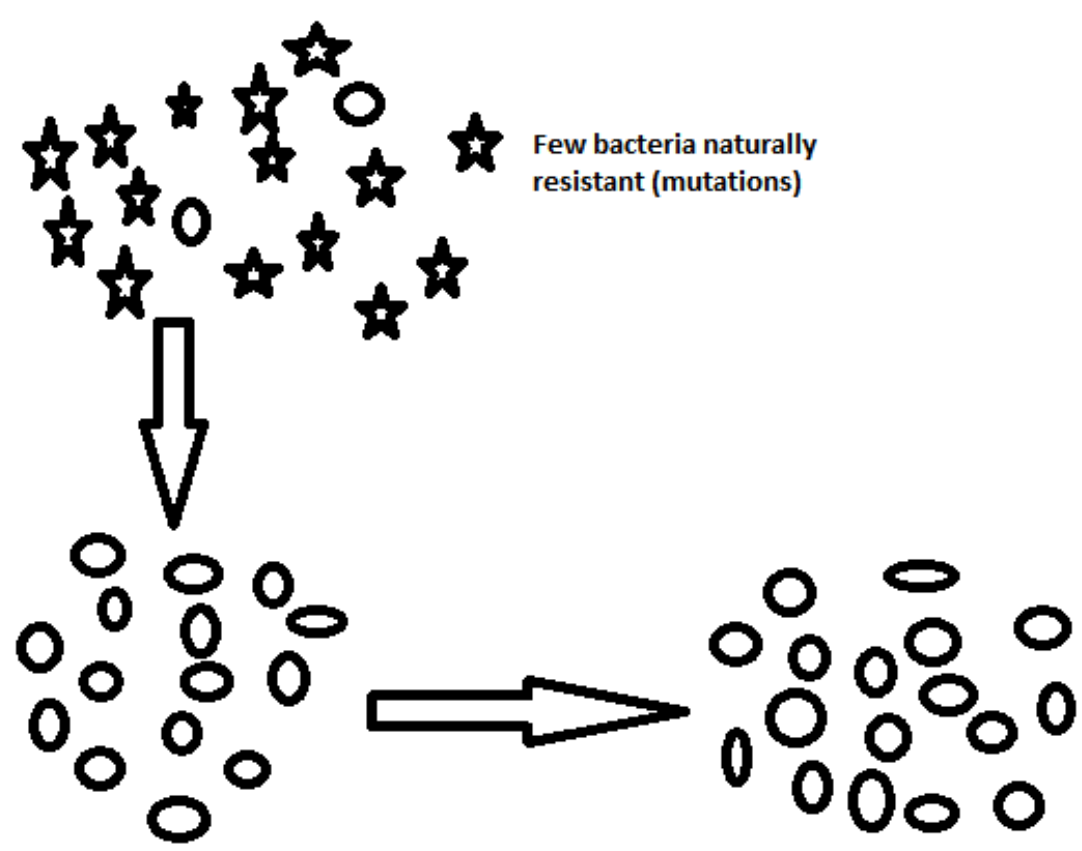

Acquired resistance

overgrowth of

Primary resistant

resistant (mutant)

transmission to

bacteria in the same

different host

host

Fig.1 Acquired and primary resistance mechanism.

The RNTCP views the treatment of MDR-TB patients as a "standard of care" issue. Recognizing that the treatment of MDR-TB cases is very complex, the treatment will follow the internationally recommended DOTS-Plus guidelines and will be done in designated RNTCP DOTS-Plus sites. 
Multidrug Resistant Tuberculosis; a Pharmacological view based.....

\section{DOTS-PLUS: Category IV regimen for MDR-TB}

RNTCP will be using a Standardized Treatment Regimen (Cat IV) for the treatment of MDR-TB cases under the programme. Cat IV regimen comprises of 6 drugs (Kanamycin, Ofloxacin, Ethionamide, Pyrazinamide, Ethambutol and Cycloserine) during 6-9 months of the Intensive Phase and 4 drugs (Ofloxacin, Ethionamide, Ethambutol and Cycloserine) during the 18 months of the Continuation Phase. P-aminosalicylic acid (PAS) is included in the regimen as a substitute drug if any bactericidal drug (Kanamycin, Ofloxacin, Ethionamide and Pyrazinamide) or 2 bacteriostatic (Ethambutol and Cycloserine ) drugs are not tolerated .

Table.2 DOTS compared to DOTS-Plus Strategy

\begin{tabular}{|l|l|}
\hline DOTS & DOTS-Plus \\
\hline $\begin{array}{l}\text { DOTS prevent emergence of drug resistant TB and } \\
\text { MDR-TB }\end{array}$ & $\begin{array}{l}\text { DOTS -Plus design to cure MDR-TB using second } \\
\text { line drugs. }\end{array}$ \\
\hline $\begin{array}{l}\text { Make primarily use of } 1^{\text {st }} \text { line drugs that are less } \\
\text { expensive. }\end{array}$ & $\begin{array}{l}\text { Make use of } 2^{\text {nd }} \text { line drugs that are more toxic and } \\
\text { expensive, difficult to treat, less effective to } \\
\text { administrate and often poorly tolerated. }\end{array}$ \\
\hline & $\begin{array}{l}\text { DOTS- Plus needed in area where MDR-TB has } \\
\text { emerged due to previous inadequate TB control. }\end{array}$ \\
\hline $\begin{array}{l}\text { DOTS-Plus only recommended in setting where } \\
\text { DOTS strategy is fully in place to prevent against the } \\
\text { development of further drug resistance. }\end{array}$ \\
\hline
\end{tabular}

Revised National Tuberculosis Control Programme, DOTS-Plus Guidelines FEB-2009

\section{Drug dosages and administration}

All drugs should be given in a single daily dosage under directly observed treatment (DOT) by a DOT provider (Table.3). All patients will receive drugs under direct observation for 6 days of the week. On the $7^{\text {th }}$ day (Sunday) the oral drugs will be administered unsupervised whereas injection kanamycin will be omitted. If intolerance occurs to the drugs, ethionamide, cycloserine and PAS may be split into two dosages and the morning dose administered under DOT. The evening dose will be self-administered. The empty blister packs of the self-administered doses will be checked the next morning during DOT. Pyridoxine at a dose of 100mg should be administered to all patients on an RNTCP Category IV regimen.

Table.3 Dosage and weight band recommendations

\begin{tabular}{|l|l|l|l|}
\hline Drugs & $16-25 \mathrm{Kgs}$ & $26-45 \mathrm{Kgs}$ & $>45 \mathrm{Kgs}$ \\
\hline Kanamycin & $500 \mathrm{mg}$ & $500 \mathrm{mg}$ & $750 \mathrm{mg}$ \\
\hline Ofloxacin & $400 \mathrm{mg}$ & $600 \mathrm{mg}$ & $800 \mathrm{mg}$ \\
(Levofloxacin) & $(200 \mathrm{mg})$ & $(500 \mathrm{mg})$ & $(750 \mathrm{mg})$ \\
\hline Ethionamide & $375 \mathrm{mg}$ & $500 \mathrm{mg}$ & $750 \mathrm{mg}$ \\
\hline Ethambutol & $400 \mathrm{mg}$ & $800 \mathrm{mg}$ & $1000 \mathrm{mg}$ \\
\hline Pyrazinamide & $500 \mathrm{mg}$ & $1250 \mathrm{mg}$ & $1500 \mathrm{mg}$ \\
\hline Cycloserine & $250 \mathrm{mg}$ & $500 \mathrm{mg}$ & $750 \mathrm{mg}$ \\
\hline PAS & $5 \mathrm{gm}$ & $10 \mathrm{gm}$ & $12 \mathrm{gm}$ \\
\hline Pyridoxine & $50 \mathrm{mg}$ & $100 \mathrm{mg}$ & $100 \mathrm{mg}$ \\
\hline
\end{tabular}

Revised National Tuberculosis Control Programme, DOTS-Plus Guidelines FEB-2009

\section{Monitoring for early detection of adverse reactions}

Close monitoring of patients is necessary to ensure that the adverse effects of Category IV anti-TB drugs (DOTS-Plus regimens) are recognized early by the DOT provider (table.4).$^{10}$ DOTS makes it possible to closely monitor patients and addresses the following:

Monitoring for early detection of adverse reactions

Commonly encountered adverse reactions with second line drugs

Strategies for managing adverse reactions. 
Multidrug Resistant Tuberculosis; a Pharmacological view based.....

Table.4 Common adverse reactions to the drugs used

\begin{tabular}{|c|c|}
\hline Kanamycin (Aminoglycosides) ${ }^{11,12}$ & Ototoxicity, nephrotoxicity, vertigo, electrolyte imbalance. \\
\hline Ofloxacin (Quinolones) $^{13,14}$ & $\begin{array}{l}\text { Gastro intestinal symptoms: diarrhea, vomiting, and abdominal pain, } \\
\text { central nervous system (CNS): dizziness and convulsions, } \\
\text { phototoxicity and photosensitivity, tendinopathy and tendinitis } \\
\text { nephrotoxicity skin rash cardiotoxicity arthralgia }\end{array}$ \\
\hline Ethambutol & Visual disturbance \\
\hline Pyrazinamide & $\begin{array}{l}\text { Arthralgia, hyperuricaemia, hepatitis, } \\
\text { pruritis with or without rash }\end{array}$ \\
\hline Ethionamide & $\begin{array}{l}\text { Gastro-intestinal: epigastric discomfort, anorexia, nausea, metallic } \\
\text { taste, vomiting, excessive salivation, and sulfurous belching } \\
\text { psychiatric: hallucination and depression ,hepatitis ,hypothyroidism } \\
\text { and goitre with prolonged administration, gynaecomastia, menstrual } \\
\text { disturbances, impotence, acne, headache, and peripheral neuropathy }\end{array}$ \\
\hline Cycloserine. $^{15}$ & $\begin{array}{l}\text { CNS: dizziness, slurred speech, convulsions, headache, tremor, and } \\
\text { insomnia, psychiatric: confusion, depression, altered behaviour, and } \\
\text { suicidal tendency, hypersensitivity reaction }\end{array}$ \\
\hline PAS & $\begin{array}{l}\text { Gastro-intestinal: anorexia, nausea, vomiting, and abdominal } \\
\text { discomfort, skin rash, hepatic dysfunction } \\
\text { hypokalemia, hypothyroidism and goitre with prolonged } \\
\text { administration. }\end{array}$ \\
\hline
\end{tabular}

Revised National Tuberculosis Control Programme, DOTS-Plus Guidelines FEB-2009

Adverse effects, suspected drugs, and management strategies

Gastro-intestinal symptoms (nausea and vomiting): This may be due to the bulk of drugs and/or due to ethionamide, PAS, pyrazinamide and ethambutol. Patients who complain of nausea or vomiting can be advised to take the drugs embedded in a banana. If vomiting persists, drugs will be administered one hour after one tablet of domperidone and/or a course of proton pump inhibitor or $\mathrm{H} 2$ receptor inhibitor (omeprazole, famotidine, ranitidine).

Giddiness: Giddiness could be due to aminoglycosides, ethionamide, quinolone and/or pyrazinamide. Whenever a patient complains of giddiness, over sleepiness or poor concentration, patients need to be counseled.

Ocular toxicity: Whenever a patient complains of blurring of vision or disturbance in colour vision, ethambutol should be withheld.

Renal toxicity: Common offending drug is an aminoglycoside. During treatment, blood urea and serum creatinine should be done every month for the first three months after treatment initiation and then every three months thereafter whilst injection kanamycin is being administered.

Arthralgia: The offending drugs are likely to be pyrazinamide and/or quinolones. Patients who complain of arthralgia will be prescribed paracetamol 500mg three times a day or aspirin $300 \mathrm{mg}$ three times a day. If there is no improvement after one week, a non-steroidal anti-inflammatory drug will be prescribed (e.g. ibuprofen 200mg three times a day).

Cutaneous reactions: If there is a generalized erythematous rash, especially if it is associated with fever and/or mucous membrane involvement, all drugs should be withheld immediately. When the rashes subside, the medications can be restarted one by one, at intervals of 2-3 days. The order of reintroduction will be ethambutol, cycloserine, ethionamide, quinolones, kanamycin and lastly pyrazinamide.

Hepatitis: This could be due to the combined effect of potentially hepatotoxic drugs such as pyrazinamide and ethionamide. If the liver function test results are abnormal ethionamide and pyrazinamide are to be withheld, and the other drugs continued.

Neurological symptoms: In case of peripheral neuropathy the common offending drugs are cycloserine and ethionamide. To prevent the occurrence of such adverse reaction, all patients on an RNTCP Category IV regimen should receive daily pyridoxine $100 \mathrm{mg}$. If peripheral neuropathy develops, an additional $100 \mathrm{mg}$ pyridoxine will be given. In case of seizures the offending drug could be either quinolones and/or cycloserine. If a patient develops seizures these drugs will be withheld and the patient will be referred to a neurologist for opinion.

Psychiatric disturbances: The common offending drugs are cycloserine, quinolones and/or ethionamide. In cases of suicidal tendencies and other psychiatric disturbances, the first offending drug is cycloserine, followed 
by ethionamide and quinolones. These drugs will be withheld and further management of the patient will be done in consultation with the psychiatrist. ${ }^{16}$

Vestibulo-auditory disturbances: Offending drug is usually the aminoglycosides. Patient may present with tinnitus, unsteady gait or loss of hearing. Aminoglycoside will be withheld and patient referred for a specialist opinion.

Hypothyroidism: The offending drugs are usually PAS and/or ethionamide and the combination of these drugs may increase the possibility for the same. Patients may present with slowing of activities, puffiness of face and/or thyroid swelling. Patients need to be evaluated for hypothyroidism and if present, may be treated with thyroxin.

\section{MDR-TB in special situations}

DOTS-Plus (MDR-TB) in pregnancy: teratogenicity has been demonstrated in only a few of the drugs used to treat MDR-TB, all except ethambutol have uncertain safety information available. This all makes treating MDRTB during pregnancy very challenging

All women of childbearing age who are receiving MDR-TB therapy should be advised to use birth control measures because of the potential consequences for both mother and fetus resulting from frequent and severe adverse drug reactions. It should be remembered that oral contraceptives might have decreased efficacy due to vomiting and drug interactions with MDR-TB drugs. ${ }^{17,18,19}$

\section{MDR-TB with HIV co-infection}

The treatment of HIV positive individual with MDR-TB is the same as for HIV negative patients. However treatment is more difficult and adverse events more common. (table.5)

Table.5 DOTS-Plus regimen's Interaction potential with antiretroviral drugs:

\begin{tabular}{|c|c|c|c|}
\hline $\begin{array}{l}\text { DOTS-Plus } \\
\text { regimen's drug } \\
\text { classes }\end{array}$ & Protease inhibitor & NNRTIs & NRTIs \\
\hline Aminoglycosides & $\begin{array}{l}\text { Interactions unlikely. Use } \\
\text { standard doses but monitor } \\
\text { renal function. }\end{array}$ & $\begin{array}{l}\text { Interactions unlikely Use standard } \\
\text { doses but monitor renal function }\end{array}$ & $\begin{array}{l}\text { Interactions unlikely Use } \\
\text { standard doses but monitor } \\
\text { renal function }\end{array}$ \\
\hline Thioamides: & $\begin{array}{l}\text { Risk of hepatoxicity with } \\
\text { tipranavir } \\
\text { and darunavir. }\end{array}$ & $\begin{array}{l}\text { Risk of hepatoxicity with } \\
\text { Efavirenz and nevirapine. }\end{array}$ & $\begin{array}{l}\text { No studies have been } \\
\text { performed, interactions } \\
\text { difficult to predict. }\end{array}$ \\
\hline Cycloserine & $\begin{array}{l}\text { No studies have been } \\
\text { performed }\end{array}$ & $\begin{array}{l}\text { Monitor for psychiatric morbidity } \\
\text { with efavirenz. }\end{array}$ & $\begin{array}{l}\text { No studies have been } \\
\text { performed }\end{array}$ \\
\hline Fluoroquinolone & $\begin{array}{l}\text { Interactions with ofoxacin, } \\
\text { levofoxacin or gatifoxacin } \\
\text { Are not predicted. } \\
\text { Cause prolongation of the } \\
\text { QT interval and should be } \\
\text { used with caution with } \\
\text { other agents that do the } \\
\text { same, including PIs. }\end{array}$ & $\begin{array}{l}\text { Cause prolongation of the QT } \\
\text { interval and should be used with } \\
\text { caution with other agents that do } \\
\text { the same, including efavirenz. }\end{array}$ & $\begin{array}{l}\text { Oral absorption is reduced } \\
\text { by buffered drugs.No } \\
\text { studies have been } \\
\text { performed, interactions } \\
\text { difficult to predict. }\end{array}$ \\
\hline PAS: & $\begin{array}{l}\text { No studies have been } \\
\text { performed but interactions } \\
\text { unlikely. }\end{array}$ & $\begin{array}{l}\text { No studies have been performed } \\
\text { But interactions unlikely. }\end{array}$ & $\begin{array}{l}\text { No studies have been } \\
\text { performed } \\
\text { But interactions unlikely. }\end{array}$ \\
\hline
\end{tabular}

NNRTIs, non nucleoside reverse transcriptase inhibitors; NRTIs, nucleoside reverse transcriptase inhibitors; PI, protease inhibitor. Other possible reinforcing drugs (Third line drugs)

Amoxicillin with clavulanic acid: Beta-Lactam antibiotics have had a very limited role in the treatment of TB because mycobacteria produce beta-lactamase. Amoxicillin with clavulanic acid has been used at high doses in multi drug regimens against TB with some success. ${ }^{22}$ Amoxicillin is commonly used in individuals with HIV infection and interactions with antiretroviral are unlikely. The addition of a beta-lactamase inhibitor to amoxicillin greatly improves its in vitro activity against M. tuberculosis. ${ }^{23}$

Clarithromycin: a semi-synthetic, second generation macrolide, clarithromycin, is effective against Mycobacterium avium-complex, and other NTM (Non-tubercular mycobacteria) including M. para tuberculosis. It is also recommended in the treatment of infections caused by Mycobacterium marinum and Mycobacterium 
fortuitum complex. It has been shown to cause a reduction in the bacillary load and clinical improvement of M. avium disease in AIDS patients. When administered orally it undergoes first- pass metabolism so that the bioavailability is 55\%. It can also be given intravenously. Interactions between Clarithromycin and several antiretroviral have been studied. Simultaneous co-administration of Clarithromycin reduces zidovudine concentrations, but no reduction is seen if Clarithromycin and zidovudine are given at least $2 \mathrm{hrs}$ apart. ${ }^{24}$

Linezolid : Linezolid is a new synthetic antibacterial agent of the oxazolidinone class, which has recently been used in Successful regimens against MDR-TB. ${ }^{25}$ However, long term toxicities are concerning. Linezolid can cause reversible myelosuppression ${ }^{26,27}$ and should be used cautiously in patients with preexisting cytopaenias, including those with anemia on zidovudine. Prolonged courses of linezolid have been associated with lactic acidosis and optic or peripheral neuropathy and appear to inhibit mitochondrial protein synthesis. ${ }^{28,29,30}$ It would therefore be advisable not to co-administer other drugs, which suppress mitochondrial activity such as didanosine, stavudine, and to a lesser extent zidovudine.

Clofazimine: Clofazimine is a substituted iminophenazine bright-red dye that inhibits mycobacterial growth and binds preferentially to mycobacterial DNA causing inhibition of transcription. The MlCs of clofazimine against M. tuberculosis have not been published. Adverse reactions include discoloration of the skin, gastrointestinal upset, severe and life-threatening abdominal pain and organ damage caused by clofazimine crystal deposition, and asymptomatic discoloration of the eye. ${ }^{31,32}$

Amikacin: Amikacin, an aminoglycoside, is highly bactericidal against M. tuberculosis. It is given five days a week in a dose of $15 \mathrm{mg} / \mathrm{kg} / \mathrm{day}$ as a single dose, usually by intramuscular injection. The major side effect of amikacin is nephrotoxicity and vestibular damage. Hearing loss, hypocalcaemia, hypokalaemia and hypomagnesaemia are other side effects. In comparison to kanamycin, it is less ototoxic and less painful. ${ }^{33}$

Capreomycin: Capreomycin is an aminoglycoside which is bactericidal against M. tuberculosis. It is given in a dose of $15 \mathrm{mg} / \mathrm{kg} /$ day intramuscularly with maximum of $1 \mathrm{Gram}$. It is toxic to the eighth cranial nerve, causing high frequency hearing loss in 3.2 to $9.4 \%$ of patients before vestibular dysfunction occurs. Renal toxicity is somewhat more common with capreomycin than with streptomycin, and it may be associated with electrolyte disturbances secondary to tubular damage. It is suggested that in elderly patients when there is similar susceptibility to capreomycin and amikacin, capreomycin should be used since older patients seem to experience more renal and ototoxic effects with amikacin than with capreomycin. ${ }^{33}$

\section{CONCLUSION}

DOTS is a established cost-effective TB treatment strategy. A blend of technical and managerial components, DOTS quickly makes infectious cases non-infectious and breaks the cycle of transmission. Using DOTS also prevents the development of drug-resistant strains of TB that are often fatal and very expensive to cure. ${ }^{34}$ Multi-drug-resistant TB is both an individual misfortune and a manifestation of poor program performance. The top priority is to prevent the emergence of MDR-TB by ensuring a low default rate of cases treated with first-line anti-TB drugs. If MDR-TB has emerged in a certain area, it should be treated in addition to improving the basic treatment. In this situation, accurate and reliable dug susceptibility testing, methods to support patients in order to ensure direct observation of complete treatment, and the use of maximally effective regimens must be ensured. Patients with MDR-TB have a good chance for a cure with second-line drugs, hence the treatment, if it is to be provided, should be optimally selected and administered ${ }^{35}$ Second-line drugs should not be kept in reserve and the treatment observation must be ensured.

Second-line TB drugs include in DOTS-Plus strategy are characterized by varied metabolic pathways. Some of these are among the oldest antimicrobials introduced into clinical practice, others have been newly approved.

Pharmacology of second-line TB drugs is elementary to managing MDR-TB in the shadow of escalating HIV epidemic especially where patients are intolerant of first-line TB drugs. MDR-TB is emerging epidemic and its management is challenging. Further needs to be done in resource-poor settings, in which the burden of HIV/ TB co-infection is greatest. The burden of MDR-TB can be reduced by better implementation of DOTS to rapidly identify, trace and re-instate treatment in poorly adherent patients receiving first-line TB drugs. So even though we have DOTS-Plus (second line TB drugs) the crucial element of whole strategy is to strengthening of DOTS (first line TB drugs) to preclude emergence of MDR-TB. 


\section{REFERENCES}

[1]. Pablos-Méndez A, Raviglione MC, Laszlo A, et al. Global surveillance for antituberculosis drug resistance, 1994-1997. N Engl J Med 1998;338:1641-49.

[2]. Espinal MA, Laszlo A, Simonsen L, et al. Global trends in resistance to antituberculosis drugs. N Engl J Med 2001;344:12941303.

[3]. World Health Organization. Treatment of tuberculosis (rev 3). WHO/CDS/TB/2003.313. Geneva: WHO, 2003.

[4]. Lambregts-van Weezenbeek C S B, Veen J. Control of drug- resistant tuberculosis. Tubercle Lung Dis 1995; 76 : $455-459$.

[5]. Espinal MA, Kim SJ, Suarez PG, et al. Standard short-course chemotherapy for drug-resistant tuberculosis; treatment out- comes in six countries. JAMA 2000;283:2537-45.

[6]. World Health Organization. DOTS-Plus: preliminary results and emerging issues. Proceedings of the Meeting of the Stop TB Working Group on DOTS-Plus for MDR-TB. Tallinn, Estonia. 10-12 April 2002. WHO/CDS/TB/2002.307. Geneva: WHO, 2002.

[7]. Mahadev B, Kumar P, Agarwal SP, Chauhan LS, Srikantaramu N. Surveillance of drug resistance to anti-tuberculosis drugs in districts of Hoogli in West Bengal and Mayurbhanj in Orissa. Indian J Tuberc 2005:52;5-10.

[8]. Paramasivan CN, Venkataraman P, Chandrasekaran V, Bhat S,Narayanan PR. Surveillance of drug resistance in tuberculosis in two districts of South India. Int J Tuberc Lung Dis 2002:6;479-484.

[9]. Central TB Division, Directorate General of Health Services, Ministry of Health \& Family Welfare. DOTS-Plus Guidelines FEB2009. Nirman Bhavan, New Delhi: Revised National Tuberculosis Control Programme. p. 39-54.

[10]. Furin JJ, Mitnick CD, Shin SS et al. Occurrence of serious adverse effects in patients receiving community-based therapy for multidrug-resistant tuberculosis. Int J Tuberc Lung Dis 2001;5:648-55.

[11]. Moore RD, Smith CR, Lietman PS. Risk factors for the development of auditory toxicity in patients receiving aminoglycosides. J Infect Dis 1984;149:23-30.

[12]. de Jager P, van Altena R. Hearing loss and nephrotoxicity in long-term aminoglycoside treatment in patients with tuberculosis. Int J Tuberc Lung Dis 2002;6:622-27.

[13]. Arora VK, Tumbanatham A. Severe arthropathy with ofloxacin in two cases of MDR tuberculosis. Int J Tuberc Lung Dis 1998;2:941-3.

[14]. Yew WW, Chan $\mathrm{CK}$, Chau $\mathrm{CH}$, et al. Outcomes of patients with multidrug-resistant pulmonary tuberculosis treated with ofloxacin/levofloxacin containing regimens. Chest 2000;117:744-51.

[15]. Akula SK, Aruna AS, et al. Cycloserine-induced Stevens-Johnson syndrome in an AIDS patient with multidrug- resistant tuberculosis. Int J Tuberc Lung Dis 1997;1:187-90.

[16]. Vega P, Sweetland A, Acha J, et al. Psychiatric issues in the management of patients with multidrug-resistant tuberculosis. Int J Tuberc Lung Dis 2004;8:749-758.

[17]. Drobac PC, del Castillo H, Sweetland A, Anca G, Joseph JK, Furin J, Shin S. Treatment of multidrug-resistant tuberculosis during pregnancy: long-term follow-up of 6 children with intrauterine exposure to second-line agents. Clin Infect Dis 2005;40:1689-92.

[18]. Shin S, Guerra D, Rich M, Seung KJ, Mukherjee J, Joseph K, Hurtado R, Alcantara F, Bayona J, Bonilla C, Farmer P, Furin J. Treatment of multidrug-resistant tuberculosis during pregnancy: a report of 7 cases. Clin Infect Dis 2003;36:996-1003.

[19]. Duff P. Antibiotic selection in obstetric patients. Infect Dis Clin North Am.1997;11:1-12.

[20]. Anson BD,Weaver JG, Ackerman MJ, Akinsete O, Henry K, January CT, et al. Blockade of HERG channels by HIV protease inhibitors. Lancet 2005;365:682-86.

[21]. Castillo R, Pedalino RP, El-Sherif N, Turitto G. Efavirenz-assoCiated QT prolongation and torsade de pointes arrhythmia. Ann Pharmacother 2002;36:1006-8.

[22]. Nadler JP, Berger J, Nord JA, Cofsky R, Saxena M. Amoxicillin-clavulanic acid for treating drug-resistanct Mycobacterium tuberculosis. Chest 1991;99:1025-26.

[23]. Wong CS, Palmer GS, Cynamon MH. In vitro susceptibility of Mycobacterium tuberculsis, Mycobacterium bovis and Mycobacterium kansasii to amoxycillin and ticarcillin in combination with clavulanic acid. $\mathrm{J}$ Antimicrob Chemother 1968;22:663-6.

[24]. Polis MA, Piscitelli SC, Vogel S,Witebsky FG,Conville PS, Petty B, et al. Clarithromycin lowers plasma zidovudine levels In persons with human immuno deficiency virus infection. Antimicrob Agents Chemother 1997;41:1709-14.

[25]. Fortún J, Martín-Dávila P, Navas E, Pérez-Elías MJ, Cobo J, Tato M, et al. Linezolid for the treatment of multidrug Resistant tuberculosis. J Antimicrob Chemother 2005;56:180-5.

[26]. Green SL, Maddox JC, Huttenbach ED. Linezolid and reversible myelosuppression. JAMA 2001;285:1291

[27]. Bishop E, Melvani S, Howden BP, Charles PG, Grayson ML. Good clinical outcomes but high rates of adverse reactions During linezolid therapy for serious infections: a proposed Protocol for monitoring therapy in complex patients. Antimicrob Agents Chemother 2006;50:1599-1602.

[28]. De Vriese AS, Coster RV, Smet J, Seneca S, Lovering A, Van Haute LL, et al. Linezolid -induced inhibition of mitochondrial protein synthesis. Clin Infect Dis 2006;42:1111-17.

[29]. Garrabou G, Soriano A, López S, Guallar JP, Giralt M, Villarroya F, et al. Reversible inhibition of mitochondrial protein synthesis during linezolid-related hyperlactatemia. Antimicrob Agents Chemother 2007;51:962-67.

[30]. Rubinstein E, Isturiz R, Standiford HC, Smith LG, Oliphant TH, Cammarata S, et al. Worldwide assessment of linezolidís clinical safety and tolerability: comparator-controlled phase III studies. Antimicrob Agents Chemother 2003;47:1824-31.

[31]. Arbiser JL, Moschella SL.Clofazimine: are view of its medical Uses and mechanisms of action. J Am Acad Dermatol 1995;32:241-47.

[32]. Holdiness MR. Clinical pharmacokinetics of clofazimine: a review. Clin Pharmacokinet 1989; 16:74-85.

[33]. HoYI,Chan CY,Cheng AF. In-vitro activities of aminoglycoside-aminocyclitols against mycobacteria. J Antimicrob Chemother 1997; 40:27-32.

[34]. WHO, Geneva, Switzerland. What is DOTS? A guide to understanding the WHO recommended TB control strategy known as DOTS 1999; WHO/CDS/CPC/TB/99.270:5

[35]. Frieden TR, Khatri GR. Multi Drug Resistant Tuberculosis In: Tuberculosis, Epidemiology and Control, Vol. 1. New Delhi: WHO, Regional Office for South East Asia; p. 105-15. 